\title{
TRANSIENT PROCESSES OF VIBRATION MACHINES WITH INERTIAL ELECTRIC DRIVES
}

\author{
Kamoliddin Alimkhodjaev ${ }^{1}$, Murakam Mirsaidov ${ }^{1}$, Malika Khalikova $^{1}$, Jasurbek Nizamov ${ }^{1}$ \\ ${ }^{1}$ Tashkent State Technical University, Department of Electrical machine, Tashkent, 100095, Uzbekistan
}

\begin{abstract}
In order to conduct model experimental studies of the mutual influence of electromagnetic and mechanical transient processes of starting up inertial vibration drives with an asynchronous motor, its mathematical model is being developed. The analytical dependence of the dynamic mechanical characteristics of the vibrator at various values of the rotor acceleration is determined. The mathematical model uses the dynamic mechanical characteristics of an induction motor as a torque.
\end{abstract}

\section{Introduction}

The tasks set for solution in our country for the next period of time for the intensive development of the national economy require the use of modern technologies for the production and processing of raw materials [1]. At the same time, increasing labor productivity, producing high-quality and competitive products with minimal material, energy and labor costs, based on the use of the latest achievements of domestic and foreign science, technology and technology, are at the forefront of the tasks. The solutions to these problems depend on the design and construction of multifunctional machines that facilitate the creation of an automated production line.

Vibration machines (VM) are used in various sectors of the national economy to create vibration of the working organs of production mechanisms. Inertial vibration drives (IVD) with asynchronous motors (AM) with a squirrel-cage rotor are mainly used as VM electric drives [2]. Despite their widespread use in industrial installations, significant potential opportunities remain unused. The implementation of these possibilities is associated with the need to automate the tuning processes into the resonance mode and control the transient processes of starting up and stopping the electric drive. The resonant nature of the operation of the $\mathrm{VM}$, a peculiar change in the dynamic mechanical characteristics, the nonlinear dependence of the acceleration of the rotor with varying the speed of its rotation do not allow to correctly perform experimental studies of the IVD with AM.

\section{Analysis of transient processes BM}

Therefore, the purpose of this work is to analyze physical processes and study changes in controlled influences in the process of mutual influence of dynamic mechanical characteristics of $\mathrm{VM}$ and $\mathrm{AM}$ during a transient process using a mathematical model developed by the authors.

To simplify the analysis of the physical processes of transient modes, at the first stage of research, we make the assumption that the mechanical part of the oscillatory system is one mass, the elastic elements of the VM are linear, the damping forces are concentrated and proportional to the vibration speed of the working body (w.b.), an induction motor seems idealized.

In contrast to the generally accepted designations of the static mechanical characteristics of the engine $M(\omega)$ and the production mechanism $M_{c}(\omega)$, taken at fixed values of the rotor speed, we denote the dynamic mechanical characteristics of the IM (the dependence of the dynamic electromagnetic moment on the speed) $M^{\partial}(\omega)$ and the dynamic mechanical characteristics of the $\mathrm{BM}$ (the dependence of the dynamic moment of resistance of the VM on the rotor speed ) $M_{c}{ }^{\partial}(\omega)$.

The analysis of transient processes and the mutual influence of dynamic mechanical characteristics $M^{\partial}(\omega)$ and $M_{c}{ }^{\partial}(\omega)$ inertial vibration drives will be carried out using the mathematical model of the IVD with AM.

In contrast to typical electric drives, in VM, mechanical vibration of the w.b has a tangible effect on the parameters of electromagnetic and mechanical transient processes. Therefore, in the research of transient processes of the VM (for example, starting up or controlling the frequency of oscillations of the rods) using a mathematical model, the moment of resistance of the $\mathrm{VM} M_{c}{ }^{\partial}(\omega)$ is used, which includes a dynamic vibration component [3].

$$
M_{C}^{\partial}(\omega)=M_{C .0}+M_{C .0}\left(\omega / \omega_{0}\right)^{2}+M_{C . v i b}^{\partial}(\omega)
$$

The first two components of the dynamic moment of resistance of the VM are known, while the value depends $M_{c . o}(\omega)$ on the total moment of inertia of the rotor and all rotating parts of the IVD with AM. The third component $M_{c . v i b}^{\partial}(\omega)$ of dependence (1) - the dynamic vibrational moment of resistance - expresses the reverse action of the vibrated working body of the VM on the rotating 
shaft and on the variables of an induction motor is determined by the following analytical expression.

$$
M_{\mathrm{C} . v i b}(\omega)=\frac{\rho(A, \omega)}{2} \frac{A(t) \cdot \omega}{\sqrt{\left[\Omega^{2}(A, \omega)-\omega^{2}\right]^{2}+\left(\frac{\rho}{m} \cdot \omega^{2}\right)}}
$$

where $\rho(A, \omega)$ - the stiffness of elastic elements, depending on the amplitude $A$ and angular frequency of vibrations $\omega$ of the working body. In accordance with the above assumptions, $\rho(A, \omega)=\rho$ - an element with a linear characteristic; $A(t)$ - the dynamic amplitude of w.b. oscillations, which depends on time $t$ within the duration of transient processes;

$m=m_{0}+m_{1}, m_{0}$ and $m_{1}$ - the masses of the oscillatory system, unbalance and working body.

Figure 1 shows the curves of the dynamic moments $M_{C}^{\partial}(\omega)$ of resistance, built according to equations (1) and (2) at different values of the acceleration of the rotor ( $\varepsilon=d \omega / d t$ ) for the IVD with AM of the VID-2 type. It can be seen from the calculated curves $M_{C}^{\partial}(\omega)$ that with an increase in the acceleration of the rotor $\varepsilon$, the dynamic mechanical characteristic of the VM shifts to the right with respect to the static characteristic $\left(\varepsilon_{1}=0\right)$. After decay of the transient process, the dynamic mechanical characteristic of the VM returns to its original state and will be determined by the $\varepsilon_{1}$ curve (Fig. 1). Experimental confirmation of the above is faced with some difficulties associated with the inability to maintain $\varepsilon_{1}=$ const with changes in the rotor speed when starting the VM. Therefore, we will continue to study the dynamic mechanical characteristics using the mathematical model of the IVD with AM, which allow a more thorough study of the properties of the VM in dynamics.

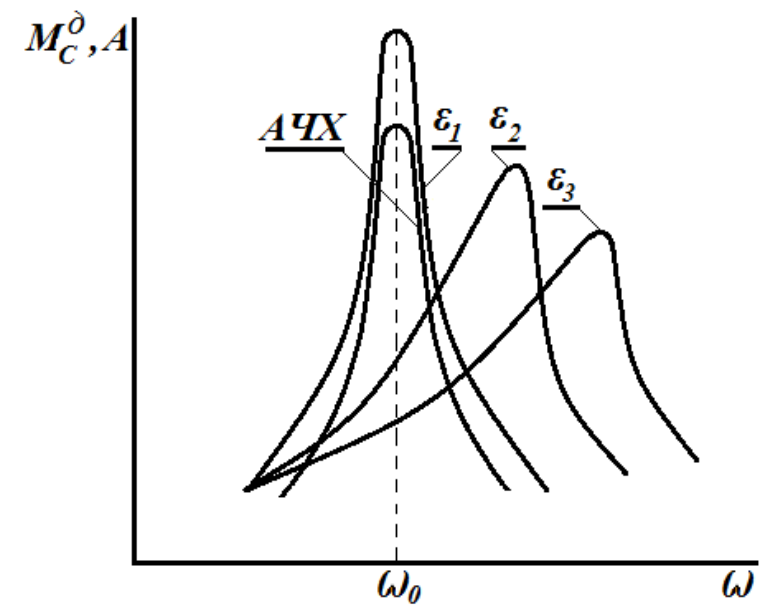

Fig. 1. Frequency response and dynamic moment of resistance

To develop a mathematical model of a vibratory machine, together with the dependences of the moments of resistance of the VM (1) - (2), we use the equations of the equilibrium of forces moving the working body - the forces of excitation of vibration and forces of resistance to motion of one mass VM [3],

$$
m \ddot{x}+\rho \dot{x}+\omega_{0}^{2} x=F_{m} \cos \omega t,
$$

Where

$$
F_{m}=m_{0} \cdot r_{\ni} \cdot \omega^{2},
$$

VM frequency response

$$
A=\frac{F_{m}}{m \cdot \sqrt{\left(\omega_{0}^{2}-\omega_{\mathrm{B}}^{2}\right)^{2}+4\left(\frac{\rho}{m \cdot \omega_{\mathrm{B}}}\right)^{2}}},
$$

Where, $x, \dot{x}$ and $\ddot{x}$ - instantaneous values of oscillations, speed and acceleration during vibration of w.b.;

$r_{\ni}$ - unbalance radius (distance between the axes of inertia and rotation);

$\omega_{0}, \omega,-$ angular frequency of free and the frequency of forced oscillations of w.b.

In addition to the above equations of the vibration drive, in the mathematical model of the vibrator we use the well-known equations for the phase voltages of the stator and rotor windings, the equilibrium of moments and the electromagnetic moment of the AM,

$$
\begin{gathered}
u_{1}=i_{1} r_{1}+\frac{d \psi_{1}}{d t}+\omega_{1} \psi_{1} ; \\
u_{2}=i_{2} r_{2}+\frac{d \psi_{2}}{d t}+\left(\omega_{1}-\omega\right) \psi_{2} ; \\
M^{\partial}(\omega)-M_{C}^{\partial}(\omega)=\frac{J}{p} \frac{d \omega}{d t} \\
M=\frac{p m_{1}}{\omega_{1}}\left(I_{2}^{\prime}\right)^{2} \frac{r_{2}^{\prime}}{s},
\end{gathered}
$$

where $J$ - the moment of inertia of rotating parts;

$u_{1}$ and $u_{2}$ - instantaneous voltage values of stator and rotor windings;

$i_{1}$ and $i_{2}$ - instantaneous values of the currents of the stator and rotor windings;

$p, r_{1}$ and $r_{2}$ - the number of pairs of poles of the AM, the values of the active resistances of the stator and rotor windings;

$\psi_{1}$ and $\psi_{2}$ - instantaneous values of flux linkages of stator and rotor windings;

$\omega_{1}$ and $\omega_{2}$ - the rotational speed of the rotating magnetic field of the stator and the rotational speed of the rotor.

In order to eliminate the complex electromagnetic connection between the phases of a three-phase winding of an induction motor, its mathematical model is transformed in a biaxial coordinate system $\alpha-\beta$ using well-known transformation methods $[4,5,8]$.

From the equations of equilibrium of motion of p.o. single-mass VM (1) and (2), it can be seen that the amplitude-frequency characteristics (AFC) and the dynamic moment of resistance of the IVD with AM have a resonant character of change. 


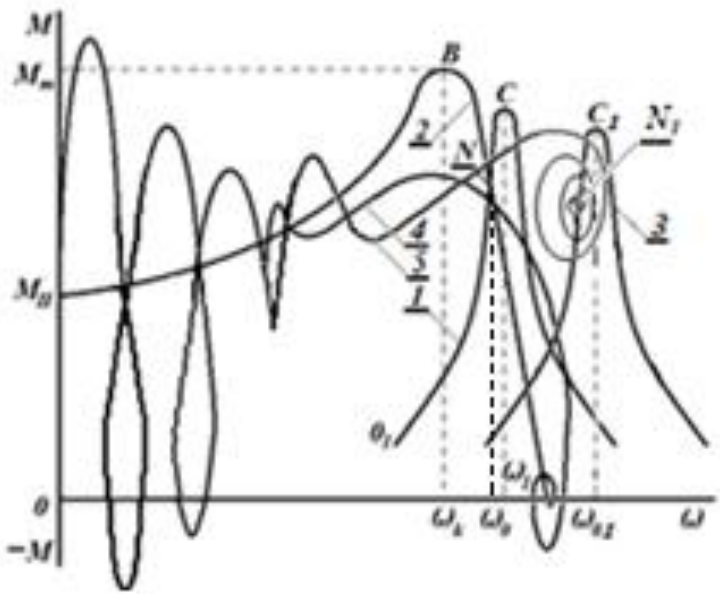

Fig. 2. Mechanical characteristics of IVD with AM

Work in the pre-resonance zone $M_{C}(t)$ (curve 1 or segment O1C, Fig. 2) is a statically stable area of the VM. On the other hand, the zone of stable operation of the induction motor is in a limitedly small section of the static mechanical characteristic in the rotor speed range $\Delta \omega=\omega_{1}-\omega_{k}$, i.e. within the working area of the mechanical characteristics $M(\omega)$ of AM (straightened part $\omega_{1} B$ of curve 2, Fig. 2). Thus, the work of the VM is statically stable at the point $N$ of the intersection of curve 1 and straight line 2 .

Consequently, the main goal of adjusting the IVD with AM to the resonant mode is to achieve the required value of the oscillation amplitude of the working element, and the main control task is to achieve the stability of the operation of the electric drive at point $\mathrm{N}$ under various external disturbing influences. Considering that with a slight change in the VM load parameters, the frequency of free oscillations.

$$
\omega_{0}=\sqrt{\rho / m}
$$

changes (increases or decreases), you can see that the frequency response and $M_{\mathrm{C}}(\omega)$ shift from point $\mathrm{N}$ to the right or left (curve 3 with the frequency $\omega_{01}$ of Fig. 2). In this case, in order to maintain the most effective mode of the AM with the maximum amplitude of the rotor oscillations, the control of the frequency of rotation of the AM rotor $\omega$ should set point $\mathrm{N}$ closer to the resonant frequency $\omega_{0}$ or $\omega_{01}$.

Thus, one of the disturbing influences on the change in the stability of work at point $N$ is the change in the parameters of the vibrated load in (10). Displacement of resonance curves (curves $\varepsilon_{1}$ илап $\varepsilon_{2}$ in Fig. 1), i.e. the very change in the rotor speed $\omega$ with acceleration $\varepsilon_{1}$ илаnd $\varepsilon_{2}$ in the process of VM control. Both of these factors negatively affect the process of controlling the setting of the IVD with AM to the resonant mode.

Figure 2 also shows the curves of the dependence of the dynamic electromagnetic torque on the rotor speed when starting the AM, in other words, the dynamic mechanical characteristics of the AM. The characteristics were taken in idle mode (curve 4) and vibration load (curve 5), obtained by solving the equations of the mathematical model (1) - (9).
With a direct start of the engine in idle mode, when the dynamic vibration component of the moment of resistance of the vibrator is absent, the fluctuation of the electromagnetic moment at the initial stage of the process is reflected in the dynamic mechanical characteristic of the AM in the form of a moment pulsation with an increase in the rotor speed (curve 4). The starting process ends with a damped oscillation of the torque near the idle point with coordinates $M=0, \omega$ $=\omega_{1}$. These conclusions coincide with the results of studies by other authors [6,7].

In the loaded mode of the VM, the electromagnetic moment at low rotor speeds will also change by pulsation, since the component of the vibration moment $M_{C .0}$ of resistance in equation (1) has a minimum value. With increasing rotor speed and approaching the vibration zone, i.e. to the static mechanical characteristic of the VM and to the point of statically stable operation (on curve 3), the process of starting the IVD with the AM ends with an oscillatory damping of the moment around the point $N_{1}$ (curve 3).

Mathematical modeling of transient processes of IVD with AM allows one to determine the degree of influence of individual parameters and phenomena on the quality and nature of the transient process, excluding other parameters and physical processes from the field of view, which cannot be carried out in experimental studies. So, for example, when performing an experiment and analyzing the physical start-up processes, in different sections of the starting characteristic, which determines the acceleration of the engine rotor, changes in the rotation speed and acceleration of the rotor will have different rates. It is not possible to determine separately the influence of each of the variables and parameters on the nature of the transient process.

Studies of transient start-up processes using a mathematical model have shown that the duration of oscillatory damping can be different [3] depending on the following factors:

- changes in the frequency of free oscillations of w.b. $\omega_{0}$ vibrating machines;

- the magnitude of the acceleration $\varepsilon$ of the rotor at the final stage of starting;

- tuning factor to resonance mode.

Let us analyze the physical processes that connect the above factors with the duration of the vibrational damping of mechanical transient processes.

1. Changes in the frequency of free oscillations of w.b. vibrating machines based on the dependence (10) can be observed:

- when the mass of the vibrated load changes, which is part of the total mass of the vibrating system $m$ and the working body $m_{l}$, shown in equation (2). For example, in vibrating feeders of a crushing shop conveyor, during vibrational movement of material, pieces of ore are periodically thrown up and are, as it were, in a suspended state. In conventional calculations, to take into account the mass of such a load, a certain averaged value is taken. In the study of instantaneous processes in the operation of the VM, such as the transient start-up process, one can observe the variable (pulsating) nature 
of the vibrated load, which leads to a periodic change in the frequency of free oscillations of the w.b. $\omega_{0}$, displacement of the frequency response and dynamic moment of resistance of the VM;

- when the stiffness $\rho$ of elastic elements changes. At the first stage of the study of the transient processes of starting up the IVD with AM using a mathematical model, the stiffness is assumed to be a constant value. In fact, $\rho(A, \omega)$ it is a non-linear function of the amplitude $A$ and angular frequency of vibrations of the working body.

2. Starting from the moment of the rotor speed up to the steady state, the value of the acceleration $\varepsilon$ of the rotor will have different values. The following parameters and variables influence the amount of rotor acceleration:

- when choosing an overestimated installed power of the induction motor. During the operation of VM, there are often cases when, when replacing a failed asynchronous motor, motors of oversized or understated power are chosen. In this case, the duration of the transient process of starting a new engine differs from the set value, this contributes to a change in the acceleration of the rotor;

- the rate of change in the frequency and amplitude of the voltage applied to the motor terminals.

3. Coefficient of tuning into the resonance mode, the value of which is influenced by the following parameters:

- vibration frequency of the working body with a steady or nominal rotor speed $\omega$;

is the frequency of free vibrations of the working body $\omega_{0}$, determined by (10).

\section{Conclusion}

Studies have shown that the developed mathematical model of the IVD with AM makes it possible to facilitate the study of the physical processes of the transient regime and to determine the degree of influence of certain parameters of the VM on the quality of transient processes and the dynamic stability of the IVD with AM.

\section{References}

1. Kamalov Tolyagan, Toirov Olimjon. The method of determining the energy-efficiency of career excavators of the mining industry // European science review, Vienna. 2016. №2. (3-4). P. 299-304.

2. Bazarov N.X. Teoriya, printsipi postroyeniya, razrabotka i vnedreniye avtomatizirovannыx vibroelektroprivodov. Diss. na soisk. uch. step. dokt. texn. nauk. MEI. - M.: 1990. -464 s.

3. Alimxodjayev K.T. Chastotno-upravlyaemie vibrodvigateli peremennogo toka. Diss. na soisk. uch. step. dokt. texn. nauk. TashGTU. -T.: 2004. - 394 s.

4. Kononenko Ye.V. Elektricheskiye mashini (spetsialniy kurs). Ucheb. Posobiye dlya vuzov. - M., «Visshaya shkola», 1975. - 279 s.

5. Kopilov I.P. Elektricheskie mashini. Ucheb. dlya vuzov /I.P. Kopilov. -3-e izd., ispr. - M.: Vissh. shk., 2002. - $607 \mathrm{~s}$.

6. Blexman I.I. Teoriya vibratsionnix protsessov i ustroystv. Vibratsionnaya mexanika i vibratsionnaya texnika. SPb: ID «Ruda i Metalli», 2013. $640 \mathrm{~s}$.

7. Bespalov V.Ya. Asinxronnie mashini v dinamicheskix rejimax raboti (Voprosi teorii, matematicheskogo modelirovaniya i razrabotki). Diss. na soisk. uch. step. d.t.n. - M: MEI. 1992. - 381 s.

8. Kamoliddin Alimkhodjaev, Olimjon Toirov, Mirzohid Taniev, Sharofiddin Alimkhodjaev. Addressing Issues and Possibility of Introducing Renewable Energy Sources in the Conditions of Uzbekistan. JCR. 2020; 7(15): 1721-1728. doi:10.31838/jcr.07.15.231. 